FACTA UNIVERSITATIS

Series: Mechanical Engineering Vol. 18, Nº 3, 2020, pp. 399 - 418

https://doi.org/10.22190/FUME200528033B

Original scientific paper

\title{
A HYBRID LBWA - IR-MAIRCA MULTI-CRITERIA DECISION-MAKING MODEL FOR DETERMINATION OF CONSTRUCTIVE ELEMENTS OF WEAPONS
}

\author{
Darko Božanić ${ }^{1}$, Aca Ranđelović ${ }^{1}$, Marko Radovanović ${ }^{2}$ Duško Tešić ${ }^{1}$ \\ ${ }^{1}$ University of Defense in Belgrade, Military Academy, Belgrade, Serbia \\ ${ }^{2} 1$ st Army Brigade, Serbian Armed Forces, Novi Sad, Serbia
}

\begin{abstract}
The paper demonstrates a model whose goal is to define the construction elements of weapons necessary to meet minimum requirements of users. The complexity of the problem, conditioned by different construction elements of weapons and specific situations of their use, is the reason for using methods of multi-criteria decisionmaking. In the paper we used the hybrid LBWA - IR-MAIRCA model. With this model, one can conduct an analysis of characteristics of the existing weapons, based on which we define the construction elements for modifying the existing and manufacturing new weapons. Regarding a large number of different types of weapons, the paper is limited to the analysis of close-quarters combat weapons. The LBWA method was used to calculate weight coefficients of the criteria. The MAIRCA method, which was modified by interval rough numbers, was used to select the best close-quarters combat weapon that has the best characteristics in accordance with the requests of the users. Based on the analysis, the users have the option to clearly and precisely define requests for improvement of the existing, and manufacturing new weapons.
\end{abstract}

Key Words: Multi-criteria Decision-making, LBWA, MAIRCA, Interval Rough Numbers, Constructive Elements

\section{INTRODUCTION}

Defining construction elements of different types of weapons is the process that must be carried out by both the constructor and the user. The user's role is to define the requests that the constructor's role is to implement. Often those requests are not aligned

Received May 28, 2020 / Accepted July 18, 2020

Corresponding author: Darko Božanić

University of Defence in Belgrade, Military academy, Pavla Jurišica Šturma 33, 11000 Belgrade, Serbia

E-mail: dbozanic@yahoo.com 
with the constructors' abilities. In order to avoid misunderstandings, we have developed a model that would be used to define requests, make improvements of the existing, or develop new weapons based on the existing ones. Due to complexity of research problems, we have used close-quarters combat weapons as an example because they take an important place while conducting modern military and police operations.

Modern military operations are conducted in a variety of operational theaters. A number of factors that follow and affect modern military operations have had an effect on the development of firearms in order to maximize the effects they have on the objective, that is, in order to accomplish the end state easier. Besides pistols, revolvers, rifles, and machine guns, close-quarters combat weapons take a significant place in modern militaries. They have been developed as a necessity to provide a high rate of fire at close distances, especially in urban environments which are very different from other environments where combat operations are conducted (close-quarters, a high number of objects, small shooting distances, horizontal and vertical sectors of fire, a high number of targets, etc.).

Close-quarters combat weapons are individual, light weapons, designed for engaging combatants at distances of up to 200 meters. Due to their practical rate of fire, they accomplish a high density of fire. Most often, they are of small sizes and weigh less than traditional rifles, and use pistol ammunition [1], which is one of the biggest differences from the traditional assault rifles. These types of weapons are most commonly used by military and police special forces as well as crews of armored vehicles, helicopters or airplanes [2].

There are a variety of close-quarters combat weapons on the market with different characteristics. Most of the armed forces have different types of close-quarters combat weapons. Design elements, quality of the material and construction reveal significant differences between these weapons in terms of their precision, rate of fire, number of malfunctions, etc. On the other hand, the requests from the military and police forces when conducting different kinds of operations are undefined. Consequently, an objective was set to develop a model able to determine those close-quarters combat weapons that are best suited for the needs of the Serbian Army. The research results are useful for acquiring new weapons as well as for determining the most suitable close-quarters combat weapons for use in the Serbian Army in the current state of affairs. The research results then serve as the base for defining construction tasks of new weapons, that is, modifications of the existing ones. Also, these research results were used for purchasing close-quarters combat weapons for the Serbian Army besides determining those close-quarters combat weapons which are best suited for the army units for conducting their combat tasks.

Previous research studies of this problem can be primarily connected to different analyses of characteristics of weapons as well as different approaches to selecting the best types of weapons. According to the resources available to the authors, the selection of the close-quarters combat weapons has not been performed by means of the multi-criteria decision-making method yet; therefore, we have considered the selection of other types of weapons. Dağdeviren et al. [3] show the selection of optimal weapons using the AHP, TOPSIS and fuzzy TOPSIS methods. Ashari and Parsaei [4] select the infantry rifle using the ELECTRA III method. Radovanović et al. [5] select the best anti-armor system of the second and third generation, using the AHP method. Jokić et al. [6] compare different calibers for automatic rifles using the VIKOR method. Brady and Goethals [7] analyze efficiency of different types of $155 \mathrm{~mm}$ projectiles using Monte Carlo simulations. A number of authors conducted comparative analyses of weapons using their characteristics. 
Jenkins and Lowrey [8] conducted a comparative analysis of the weapons in use in the United States Army as well as weapons recommended for replacement. Comparison was conducted using a quantitative analysis of the weapons characteristics "head to head". Gordon et al. [9] conducted a comparative analysis of the weapons in use in the United States Army as well as in a number of armies in the world by comparing basic combat characteristics. Radovanović et al. [10] select the most suitable anti-armor rocket system using numerical analysis of tactical and technical combat characteristics.

The complexity of the selection process and the process of defining the most desirable characteristics are the reasons behind the decision to use multi-criteria decision-making methods. A large number of methods were analyzed and due to specific problems of research, we defined a hybrid model that consists of two methods: LBWA (Level Based Weight Assessment) and MAIRCA (Multi Attributive Ideal-Real Comparative Analysis method) method, modified by interval rough numbers (IR-MAIRCA).

\section{LBWA - IR-MAIRCA MODEL}

A LBWA - IR-MAIRCA hybrid model is defined through four phases as shown in Fig. 1.

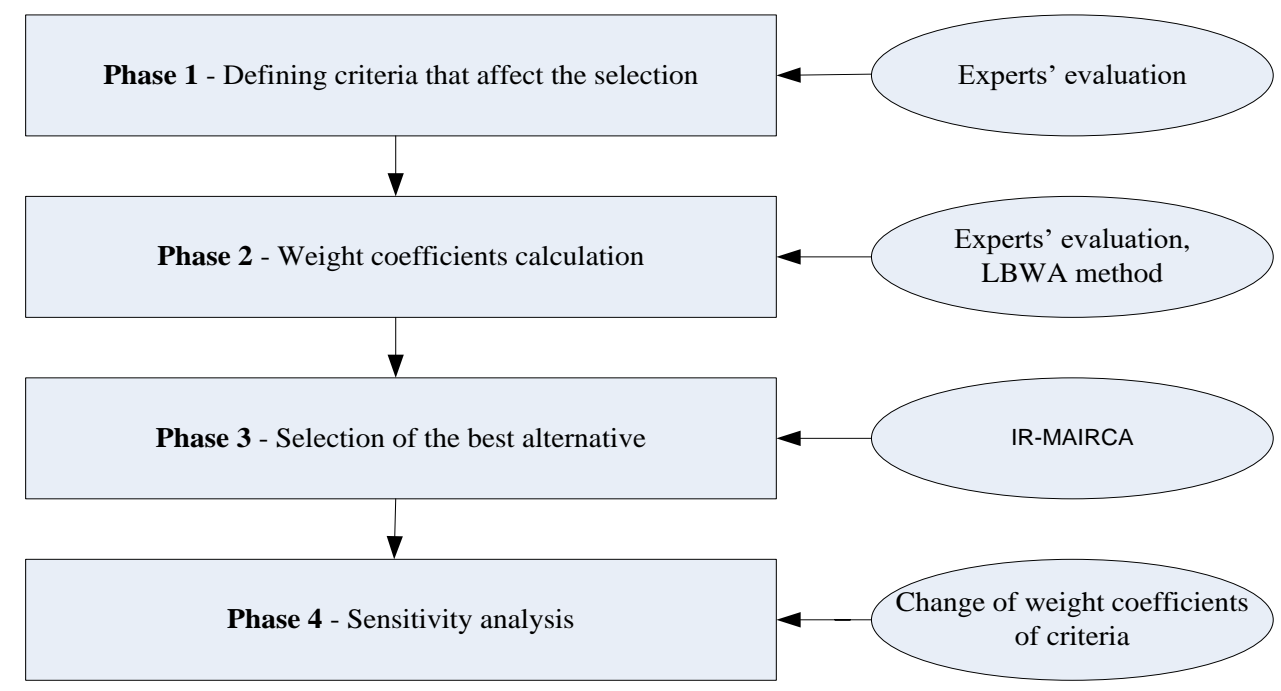

Fig. 1 LBWA - IR-MAIRCA model

In the first phase of the model, the criteria are defined using experts' evaluations that the selection of the close-quarters combat weapon depends on. In the second phase, the initial matrix was defined using expert evaluations and LBWA method to calculate weight coefficients of the criteria. In the third phase, the selection of the best alternative was conducted using the IR-MAIRCA method. In the last phase, we conducted sensitivity analysis by altering weight coefficients of the criteria. Based on the obtained results, the user 
can realistically define the requests that the new close-quarters combat weapon needs to satisfy. Further on in the paper, we show the LBWA and IR-MAIRCA methods in detail.

\subsection{LBWA method}

LBWA method is one of the newer methods for determining weight coefficients of the criteria. The model was first demonstrated in the Žižović and Pamučar paper [11]. A big advantage of this method is a relatively simple mathematical calculation, whose simplicity does not depend on the number of criteria. Also, this method can be used in both individual and group decision-making.

At the very beginning of the LBWA method, just like in many other methods, the first thing we do is to define criteria. If $n$ is the number of criteria, then we have a set $S=\left\{C_{1}, C_{2}, \ldots, C_{n}\right\}$. After defining the set of criteria (S), we start using the LBWA method that goes through following steps [11].

Step 1 Determining the most significant criterion from the set of defined criteria $S=\left\{C_{1}, C_{2}, \ldots, C_{n}\right\}$. The most significant criterion is the one which has the biggest effect on the decision, i.e. it has the biggest weight coefficient.

Step 2 Grouping criteria by the significance level. If we define the most significant criterion as $C_{1}$, in reference to it, we define which level the rest of the criteria belong to based on the following:

- Level $S_{1}$ : On level $S_{1}$ we group criteria from set $S$ whose significance is equal to the significance to criterion $C_{1}$ or up to two times less than $C_{1}$;

- Level $S_{2}$ : On level $S_{2}$ we group criteria from set $S$ whose significance is exactly two times less than $C_{1}$ or is up to three times less than $C_{1}$;

- ...

- Level $S_{k}$ : On level $S_{k}$ we group criteria from set $S$ whose significance is exactly $k$ times less than significance of $C_{1}$ or up to $k+1$ times less than significance of criterion $C_{1}$.

By using the above mentioned rules, the decision-maker makes a rough classification of the observed criteria. If the significance of a criterion $C_{j}$ is denoted by $s\left(C_{j}\right)$, where $j \in\{1,2, \ldots, n\}$, then we have $S=S_{1} \cup S_{2} \cup \cdots \cup S_{k}$, where for each level $i \in\{1,2, \ldots, k\}$, it is true that it is

$$
S_{i}=\left\{C_{i_{1}}, C_{i_{2}}, \ldots, C_{i_{s}}\right\}=\left\{C_{j} \in S: i \leq s\left(C_{j}\right)<i+1\right\}
$$

Also, for each $p, q \in\{1,2, \ldots, k\}$ such that $p \neq q$ holds $S_{p} \cap S_{q}=\varnothing$. Thus, in this way is well defined partition of the set of criteria $S$.

Step 3 Within the formed subsets (levels) of criteria influence, we compare criteria based on their significance. Each criterion $C_{i_{p}} \in S_{i}$ in the subset $S_{i}=\left\{C_{i_{1}}, C_{i_{2}}, \ldots, C_{i_{s}}\right\}$ is assigned with an integer $I_{i_{p}} \in\{0,1, \ldots, r\}$ so that the most important criterion $C_{1}$ is assigned with $I_{1}=0$, and if $C_{i_{p}}$ is more significant than $C_{i_{q}}$ then $I_{p}<I_{q}$, and if $C_{i_{p}}$ is equivalent to $C_{i_{q}}$ then $I_{p}=I_{q}$. Maximum value of the comparison scale is defined using the expression (2)

$$
r=\max \left\{\left|S_{1}\right|,\left|S_{2}\right|, \ldots,\left|S_{k}\right|\right\}
$$


Step 4 Based on the defined maximum value of criteria comparison scale $(r)$, expression (2), we define elasticity coefficient $r_{0} \in N$ (where $N$ represents a set of real numbers) that needs to meet the condition that $r_{0}>r, r=\max \left\{\left|S_{1}\right|,\left|S_{2}\right|, \ldots,\left|S_{k}\right|\right\}$. Method creators recommend that initial values of weight coefficients should be defined based on elasticity coefficients $r_{0}=r+1$. Since parameter $r_{0}$ affects smaller changes of weight coefficient changes, taking another value of elasticity coefficients is recommended for additional adjustments of the weight coefficients in accordance with personal preferences of decision-makers.

Step 5 Criteria influence function calculation. Influence function $f: S \rightarrow R$ is defined in the following way. For each criterion $C_{i_{p}} \in S_{i}$ we define a function of influence

$$
f\left(C_{i_{p}}\right)=\frac{r_{0}}{i \cdot r_{0}+I_{i_{p}}}
$$

where $i$ represents the number of levels/subsets to which the criterion is assigned, $r_{0}$ represents the elasticity coefficients, while $I_{i_{p}} \in\{0,1, \ldots, r\}$ represents the value assigned to criterion $C_{i_{p}}$ in the scope of the observed level.

Step 6 Calculation of optimal values of weight coefficients of criteria. Using expression (4) we calculate the weight coefficients of the most influential criterion:

$$
w_{1}=\frac{1}{1+f\left(C_{2}\right)+\cdots+f\left(C_{n}\right)}
$$

The weight coefficient values of the rest of the criteria are obtained using expression (5)

$$
w_{j}=f\left(C_{j}\right) \cdot w_{1}
$$

where $j=2,3, \ldots, n$, and $n$ represents the total number of criteria.

\subsection{IR-MAIRCA method}

Due to a high level of uncertainty following the decision-making processes, evident is an increase in the number of researchers who modify classical methods of multi-criteria decision-making in their papers, using different areas that address these issues in appropriate ways. Since the selection process of the close-quarters combat weapon involves uncertainty, in this paper we used the modification of the MAIRCA method using interval rough numbers. Interval rough numbers take a significant place when addressing uncertainty and there are numerous papers about them $[12,13,14,15]$.

Interval rough number IRN(A), is defined as [13]:

$$
\operatorname{IRN}(A)=\left[R N\left(A^{L}\right), R N\left(A^{\prime}\right)\right]=\left(\left[a^{L}, a^{U}\right],\left[a^{L^{L}}, a^{\prime}\right]\right)
$$

where the value $R N\left(A^{L}\right)$ represents the lower class of the IRN(A) object, which is defined by a lower $a^{L}$ and upper boundary $a^{U}$, where $a^{L} \leq a^{U}$, and value $R N\left(A^{U}\right)$ represents the upper class of the IRN (A) object, defined by the lower $a^{\prime L}$ and upper boundary $a^{\prime} U$, where $a^{\prime L} \leq a^{\prime} U$. 
Using the interval rough numbers in the MAIRCA method modification requires knowledge of the basic arithmetic operations that are specific for interval rough numbers. If we assume that there are two interval rough numbers $\operatorname{IRN}(A)=\left(\left[a_{1}, a_{2}\right],\left[a_{3}, a_{4}\right]\right)$ and $\operatorname{IRN}(B)=\left(\left[b_{1}, b_{2}\right],\left[b_{3}, b_{4}\right]\right)$, then the basic arithmetic operations with them are performed as follows [12]:

(1) Addition "+":

$$
\begin{aligned}
& \operatorname{IRN}(A)+\operatorname{IRN}(B)=\left(\left[a_{1}, a_{2}\right],\left[a_{3}, a_{4}\right]\right)+\left(\left[b_{1}, b_{2}\right],\left[b_{3}, b_{4}\right]\right)= \\
& \left(\left[a_{1}+b_{1}, a_{2}+b_{2}\right],\left[a_{3}+b_{3}, a_{4}+b_{4}\right]\right)
\end{aligned}
$$

(2) Subtraction “_"

$$
\begin{aligned}
& \operatorname{IRN}(A)-\operatorname{IRN}(B)=\left(\left[a_{1}, a_{2}\right],\left[a_{3}, a_{4}\right]\right)-\left(\left[b_{1}, b_{2}\right],\left[b_{3}, b_{4}\right]\right)= \\
& \left(\left[a_{1}-b_{4}, a_{2}-b_{3}\right],\left[a_{3}-b_{2}, a_{4}-b_{1}\right]\right)
\end{aligned}
$$

(3) Multiplication " $x$ "

$$
\begin{aligned}
& \operatorname{IRN}(A) \times \operatorname{IRN}(B)=\left(\left[a_{1}, a_{2}\right],\left[a_{3}, a_{4}\right]\right) \times\left(\left[b_{1}, b_{2}\right],\left[b_{3}, b_{4}\right]\right)= \\
& \left(\left[a_{1} \times b_{1}, a_{2} \times b_{2}\right],\left[a_{3} \times b_{3}, a_{4} \times b_{4}\right]\right)
\end{aligned}
$$

(4) Division “/”

$$
\begin{aligned}
& \operatorname{IRN}(A) / \operatorname{IRN}(B)=\left(\left[a_{1}, a_{2}\right],\left[a_{3}, a_{4}\right]\right) /\left(\left[b_{1}, b_{2}\right],\left[b_{3}, b_{4}\right]\right)= \\
& \left(\left[a_{1} / b_{4}, a_{2} / b_{3}\right],\left[a_{3} / b_{2}, a_{4} / b_{1}\right]\right)
\end{aligned}
$$

(5) Scalar multiplication where $k>0$

$$
k \times \operatorname{IRN}(A)=k \times\left(\left[a_{1}, a_{2}\right],\left[a_{3}, a_{4}\right]\right)=\left(\left[k \times a_{1}, k \times a_{2}\right],\left[k \times a_{3}, k \times a_{4}\right]\right)
$$

The MAIRCA method was first published in papers $[16,17]$. Since then it has been used in a large number of papers in its initial version [18, 19, 20, 21, 22, 23] or as a modified MAIRCA method - in fuzzy and rough environments [13, 24, 25, 26, 27, 28, 29, 30]. Modified IR-MAIRCA method has seven steps [13, 27].

Step 1 Forming initial decision-making matrix $(Y)$. As with similar methods of multicriteria decision making, the first step is to form an initial decision-making matrix, where $l$ number of alternatives is being evaluated based on $n$ number of criteria:

$$
Y=\begin{gathered}
C_{1} \\
A_{1} \\
A_{2} \\
\ldots \\
A_{l}
\end{gathered}\left[\begin{array}{cccc}
\operatorname{IRN}\left(y_{11}\right) & \operatorname{IRN}\left(y_{12}\right) & \ldots & \operatorname{IRN}\left(y_{1 n}\right) \\
\operatorname{IRN}\left(y_{21}\right) & \operatorname{IRN}\left(y_{22}\right) & & \operatorname{IRN}\left(y_{2 n}\right) \\
\ldots & \ldots & \ldots & \ldots \\
\operatorname{IRN}\left(y_{l 1}\right) & \operatorname{IRN}\left(y_{l 2}\right) & \ldots & \operatorname{IRN}\left(y_{l n}\right)
\end{array}\right]_{l \times n}
$$

where $n$ represents the total number of criteria, and $l$ represents the total number of alternatives. 
Interval rough vector $A_{i}=\left(\operatorname{IRN}\left(y_{i 1}\right), \operatorname{IRN}\left(y_{i 2}\right), \ldots, \operatorname{IRN}\left(y_{i n}\right)\right)$, where $\operatorname{IRN}\left(y_{i j}\right)=$ $\left[R N\left(y_{i j}^{L}\right), R N\left(y_{i j}^{U}\right)\right]=\left(\left[y_{i j}^{L}, y_{i j}^{U}\right],\left[y_{i j}^{\prime L}, y_{i j}^{\prime U}\right]\right)$, represents the value of the $i$-th alternative by $j$ th criterion $(i=1,2, \ldots, l ; j=1,2, \ldots, n)$.

Step 2 Determining preferences based on the choice of alternatives $P_{A_{i}}$. In the largest number of cases, the decision-makers are neutral towards the choice of alternatives. However, the MAIRCA method offers a possibility to the decision-maker to have a preference towards some of the offered alternatives and to express it through the use of the method. If the decision-maker is neutral towards the choice of the alternative, preference based on one of the $l$ alternatives is

$$
P_{A_{i}}=\frac{1}{l} ; \sum_{i=1}^{l} P_{A_{i}}=1, i=1,2, \ldots, l
$$

where $l$ represents the total number of alternatives that are selected.

Step 3 Calculation of matrix elements of theoretical estimations $\left(T_{p}\right)$. Theoretical estimations matrix elements $\left(I R N\left(t_{p i j}\right)\right)$ are interval rough numbers calculated using the following expression:

$$
\operatorname{IRN}\left(t_{p i j}\right)=P_{A i} \cdot \operatorname{IRN}\left(w_{i}\right)=P_{A i} \cdot\left[R N\left(w_{i}^{L}\right), R N\left(w_{i}^{U}\right)\right]
$$

where $P_{A_{i}}$ represents preferences towards the choice of alternatives, $\operatorname{IRN}\left(w_{i}\right)$ the weight coefficients of the evaluation, and $I R N\left(t_{p i j}\right)$ theoretical estimation of the alternative for the given criterion of evaluation. After the calculation, we get the matrix of theoretical estimations:

$$
T_{p}=\left[\begin{array}{cccc}
\operatorname{IRN}\left(t_{p 11}\right) & \operatorname{IRN}\left(t_{p 12}\right) & \ldots & \operatorname{IRN}\left(t_{p 1 n}\right) \\
\operatorname{IRN}\left(t_{p 21}\right) & \operatorname{IRN}\left(t_{p 22}\right) & & \operatorname{IRN}\left(t_{p 2 n}\right) \\
\ldots & \ldots & \ldots & \ldots \\
\operatorname{IRN}\left(t_{p l 1}\right) & \operatorname{IRN}\left(t_{p l 2}\right) & \ldots & \operatorname{IRN}\left(t_{p l n}\right)
\end{array}\right]_{l \times n}
$$

Step 4 Selecting elements of real estimations matrix $\left(T_{r}\right)$. Calculation of elements $\left(T_{r}\right)$ is performed using the expression:

$$
\operatorname{IRN}\left(t_{r i j}\right)=\operatorname{IRN}\left(t_{p i j}\right) \cdot \operatorname{IRN}\left(x_{n i j}\right)=\left(\left[t_{p i j}^{L}, t_{p i j}^{U}\right],\left[t_{p i j}^{L}, t_{p i j}^{U}\right]\right) \cdot\left(\left[x_{i j}^{L}, x_{i j}^{U}\right],\left[x_{i j}^{L}, x_{i j}^{\prime}\right]\right)
$$

where $\operatorname{IRN}\left(t_{p i j}\right)$ represents elements of the theoretical estimations matrix, and $\operatorname{IRN}\left(x_{i j}\right)$ represents elements of the normalized initial matrix of decision-making $(X)$ :

$$
\begin{aligned}
& \begin{array}{llll}
C_{1} & C_{2} & \ldots & C_{n}
\end{array} \\
& X=\begin{array}{c}
A_{1} \\
A_{2} \\
\ldots \\
A_{l}
\end{array}\left[\begin{array}{cccc}
\operatorname{IRN}\left(x_{11}\right) & \operatorname{IRN}\left(x_{12}\right) & \ldots & \operatorname{IRN}\left(x_{1 n}\right) \\
\operatorname{IRN}\left(x_{21}\right) & \operatorname{IRN}\left(x_{22}\right) & & \operatorname{IRN}\left(x_{2 n}\right) \\
\ldots & \ldots & \ldots & \ldots \\
\operatorname{IRN}\left(x_{l 1}\right) & \operatorname{IRN}\left(x_{l 2}\right) & \ldots & \operatorname{IRN}\left(x_{l n}\right)
\end{array}\right]_{l \times n}
\end{aligned}
$$


Elements of matrix $(\mathrm{X})$, that is, normalization of elements of the initial decisionmaking matrix is performed using the following expressions:

a) For criteria of the benefit type (criteria where the larger value is more desirable)

$$
\operatorname{IRN}\left(x_{i j}\right)=\left(\left[x_{i j}^{L}, x_{i j}^{U}\right],\left[x_{i j}^{L}, x_{i j}^{U}\right]\right)=\left(\left[\frac{y_{i j}^{L}-y_{i j}^{-}}{y_{i j}^{+}-y_{i j}^{-}}, \frac{y_{i j}^{U}-y_{i j}^{-}}{y_{i j}^{+}-y_{i j}^{-}}\right],\left[\frac{y_{i j}^{L}-y_{i j}^{-}}{y_{i j}^{+}-y_{i j}^{-}}, \frac{y_{i j}^{U}-y_{i j}^{-}}{y_{i j}^{+}-y_{i j}^{-}}\right]\right)
$$

b) For criteria of the „cost“ type (criteria where the smaller value is more desirable)

$$
\operatorname{IRN}\left(x_{i j}\right)=\left(\left[x_{i j}^{L}, x_{i j}^{U}\right],\left[x_{i j}^{\prime L}, x_{i j}^{\prime}\right]\right)=\left(\left[\frac{y_{i j}^{\prime}-y_{i j}^{+}}{y_{i j}^{-}-y_{i j}^{+}}, \frac{y_{i j}^{L}-y_{i j}^{+}}{y_{i j}^{-}-y_{i j}^{+}}\right],\left[\frac{y_{i j}^{U}-y_{i j}^{+}}{y_{i j}^{-}-y_{i j}^{+}}, \frac{y_{i j}^{L}-y_{i j}^{+}}{y_{i j}^{-}-y_{i j}^{+}}\right]\right)
$$

where $y_{i}^{-}$and $y_{i}^{+}$represent minimum and maximum values of the border intervals of the observed criterion, respectively:

$$
\begin{aligned}
& y_{i j}^{-}=\min _{j}\left\{y_{i j}^{L}, y_{i j}^{L^{L}}\right\} \\
& y_{i j}^{+}=\max _{j}\left\{y_{i j}^{U}, y_{i j}^{\prime U}\right\}
\end{aligned}
$$

Step 5 Calculation of the matrix of total gap $(G)$. Gap $g_{i j}$ represents interval rough number obtained using expression:

$$
\operatorname{IRN}\left(g_{i j}\right)=\operatorname{IRN}\left(t_{p i j}\right)-\operatorname{IRN}\left(t_{r_{i j}}\right)=\left(\left[t_{p i j}^{L}, t_{p i j}^{U}\right],\left[t_{p i j}^{L}, t_{p i j}^{U}\right]\right)-\left(\left[t_{r i j}^{L}, t_{r i j}^{U}\right],\left[t_{r i j}^{L}, t_{r i j}^{\prime U}\right]\right)
$$

where $\operatorname{IRN}\left(t_{p i j}\right)$ represents elements of the theoretical estimations matrix, and $\operatorname{IRN}\left(t_{r i j}\right)$ elements of real estimations matrix $\left(t_{r i j}\right)$. From the calculation, we get the matrix of total gap $(G)$ :

$$
G=\left[\begin{array}{cccc}
\operatorname{IRN}\left(g_{11}\right) & \operatorname{IRN}\left(g_{12}\right) & \ldots & \operatorname{IRN}\left(g_{1 n}\right) \\
\operatorname{IRN}\left(g_{21}\right) & \operatorname{IRN}\left(g_{22}\right) & \ldots & \operatorname{IRN}\left(g_{2 n}\right) \\
\ldots & \ldots & \ldots & \ldots \\
\operatorname{IRN}\left(g_{l 1}\right) & \operatorname{IRN}\left(g_{l 2}\right) & \ldots & \operatorname{IRN}\left(g_{l n}\right)
\end{array}\right]_{l \times n}
$$

where $n$ represents the total number of criteria, $l$ represents the total number of alternatives that are being selected, and $g_{i j}$ represents the obtained gap of alternative $i$ according to criterion $j$.

Step 6 Calculation of criteria functions values $\left(Q_{i}\right)$ by alternatives. Values of criteria functions are calculated by adding the gap - elements of matrix $(G)$ by columns:

$$
\operatorname{IRN}\left(Q_{i}\right)=\sum_{j=1}^{n} \operatorname{IRN}\left(g_{i j}\right), i=1,2, \ldots, m
$$

where $n$ represents the total number of criteria, $m$ represents the total number of alternatives that are being selected. 
Ranking the alternatives is done by converting interval rough numbers to real numbers. The conversion of interval rough number $\operatorname{IRN}\left(Q_{i}\right)=\left(\left[Q_{i}{ }^{L}, Q_{i}^{U}\right],\left[Q_{i}{ }^{L}, Q_{i}^{\prime}{ }^{\prime}\right]\right)$ into real number $Q_{i}$ is done using the expression:

$$
\begin{gathered}
\mu_{i}=\frac{R B\left(Q_{u i}\right)}{R B\left(Q_{u i}\right)+R B\left(Q_{l i}\right)} ; R B\left(Q_{u i}\right)=Q_{i}^{\prime U}-Q_{i}^{\prime L} ; R B\left(Q_{l i}\right)=Q_{i}^{U}-Q_{i}^{L} \\
Q_{i}=\mu_{i} \cdot Q_{i}^{L}+\left(1-\mu_{i}\right) \cdot Q_{i}^{U}
\end{gathered}
$$

Step 7 Determining the dominance index of the first-ranked alternative $\left(A_{D, 1-j}\right)$ and the final ranking of the alternatives. The dominance index of the first-ranked alternative represents the element that defines its advantage over other alternatives and that is why it is necessary mostly due to subjectivity during the decision-making process. By defining the dominance index, we can see the difference between the first-ranked and other alternatives more clearly. Dominance index is determined using the expression:

$$
A_{D, 1-j}=\left|\frac{\left|Q_{j}\right|-\left|Q_{1}\right|}{\left|Q_{n}\right|}\right|, j=2,3, . ., m
$$

where $Q_{1}$ represents the criteria function of the first-ranked alternative, $Q_{n}$ represents criteria function that is ranked last, $Q_{j}$ represents criteria function of the alternative used to compare the first-ranked alternative to, $m$ represents the total number of alternatives.

Besides the dominance index, in order to finish defining the first-ranked alternative, it is necessary to determine dominance threshold $I_{D}$ using the following expression:

$$
I_{D}=\frac{m-1}{m^{2}}
$$

where $m$ represents the total number of alternatives.

If the dominance index $A_{D, 1-j}$ is greater than, or equal to the threshold $I_{D}\left(A_{D, 1-j} \geq I_{D}\right)$, we keep the obtained ranking. If dominance index $A_{D, 1-j}$ is smaller than threshold $I_{D}$ $\left(A_{D, 1-j}<I_{D}\right)$, we cannot conclude with certainty that the first-ranked alternative has enough of an advantage over the observed alternative.

\section{DESCRIPTION OF CRITERIA AND CALCULATION OF WEIGHT COEFFICIENTS}

Throughout the first phase of using the model, we defined the criteria that influence the selection of the best alternatives, that is, the best close-quarters combat weapon. Defining criteria and their weight coefficients represents a significant phase for decisionmaking models [31]. Complexity and specificity of the research problem has forced us to rely on experts in order to define criteria used to make the selection. For the selection of the best alternative, we defined eight criteria shown in the next part of the paper from the most significant $\left(C_{1}\right)$ to the least significant $\left(C_{8}\right)$.

Initial velocity of the bullet $\left(C_{1}\right)$ is the velocity that the bullet reaches at the moment when it leaves the muzzle; it represents the distance in the unit of time $(\mathrm{m} / \mathrm{s})$. Larger initial 
velocity means a larger fire power of the weapon; therefore, it increases the kinetic energy of the bullet, and with that the effect (the degree of materialization) it has on the target [8]. Weapons of a smaller caliber reach a higher initial velocity of the bullet than those with a bigger caliber and, therefore, accomplish better results. A higher initial velocity gives higher accuracy and efficiency of the weapon.

Reliability $\left(C_{2}\right)$ is one of the most significant exploitational characteristics of the weapon that is expressed as the number of malfunctions proportional to the number of fired bullets (the number of malfunctions for 6000 fired bullets). It is also important for the weapon to function in different environments, in high and low temperatures, with dirty parts, in different positions of firing, etc. Experience so far shows that close-quarters combat weapons are reliable weapons; however, after a longer use, it is possible to start malfunctioning. The most common reasons for malfunctions are: wear and tear of parts, bad ammunition, bad maintenance and careless and unprofessional handling [32].

Practical rate of fire $\left(C_{3}\right)$ represents the number of bullets fired in one minute. There is a difference between theoretical and practical rate of fire. Practical rate of fire has a significant effect when conducting combat tasks. This characteristic is important for every weapon type due to its close correlation to fire density which causes greater effects on the objective. By increasing fire density, we increase the probability of hitting the target. It is expressed as the number of bullets in a minute (bullets/min). A higher rate of fire directly affects the efficiency of the weapon. Practical rate of fire is determined through experiments or calculations using the template according to Malinovski [2]:

$$
n=\frac{60}{\frac{t_{n}}{s}+t_{c}+\frac{t_{p}}{e}}
$$

where $t_{n}$ represents time, $t_{p}$ time of loading the weapon, $t_{c}$ time of one cycle of automatic work, $e$ number of bullets in a magazine and $s$ number of bullets in a burst.

Efficient range $\left(C_{4}\right)$ represents distance (in meters) up to which we can expect to hit the target with enough kinetic energy to neutralize it [33]. A higher efficient range means engaging targets at higher distances which provides greater security and protection for the shooter [10], that is, it increases the efficiency of the weapon.

Mass of the weapon $\left(C_{5}\right)$ represents the unavoidable characteristic of a close-quarters combat weapon because modern warfare demands using weapons of smaller mass. Mass of the weapon affects mobility and ability to shift fire [5]. In order to produce a weapon of small mass, manufacturers use new kinds of materials, mostly polymers. Close-quarters combat weapons made of these materials are light; however, their characteristics are the same as those made of metal. The mass is in kilograms. Smaller mass increases mobility, it is easier to handle increasing efficiency when conducting combat tasks.

Length of the weapon $\left(C_{6}\right)$ - distance (in millimeters) from the tip of the muzzle to the stock. It represents the characteristic that most affects handling and carrying the weapon. The longer the weapon, the less mobile it is and handling is more difficult in smaller space. Because of this, and in order to use the weapon more efficiently, we are leaning towards weapons smaller in size. In this way we increase mobility and provide better handling indoors [5]. Modern close-quarters combat weapons usually have collapsible stock, or the telescope type stock, that significantly reduce the length. This can significantly increase efficiency, but also reduce accuracy. 
Lifetime of the barrel $\left(C_{7}\right)$ is a characteristic defined as the number of fired bullets without affecting the characteristics of the barrel and maintaining given specifications. Manufacturing method and material are crucial for the lifetime of the barrel as well as the pressure and temperature when firing the weapon. Most common tolerable standards are $0,07 \mathrm{~mm}$ change in caliber, and damage to the barrel of less than $50 \%$.

Length of the barrel $\left(C_{8}\right)$ - Barrel is one of the main parts of the weapon; therefore, its length affects the accuracy and precision of the rifle. Longer barrels enable longer firing distances, achieving more precise and accurate results, but, at the same time, they increase mass and length of the entire weapon. When firing, the bullet rotates in the barrel for a longer time which provides a more stable travel of the bullet [34]. Also, in the longer barrels, gases have a longer effect on the bottom of the bullet and provide higher initial speeds. Unlike other automatic weapons (rifles, snipers, machine guns), close-quarters combat weapons are technically designed with shorter barrels, which means reduced precision when firing over longer distances. Therefore, they are used for accomplishing combat tasks at shorter distances. Also, the length of the barrel affects the degree of efficiency as well as materialization on the objective.

All of the listed criteria are of a numeric character and can be divided in two subsets:

- set of benefit type criteria $C^{+} \in\left\{C_{1}, C_{3}, C_{4}, C_{7}, C_{8}\right\}$,

- set of cost type criteria $C^{-} \in\left\{C_{2}, C_{5}, C_{6}\right\}$.

After determining the criteria, in the second phase of the research, we conducted the calculation of weight coefficients using the LBWA method, as described in the previous part of the paper:

Step 1 For the most significant criterion we chose $C_{1}$.

Step 2 The experts sorted the criteria in roughly 6 levels:

$$
\begin{aligned}
& S_{1}=\left\{C_{1}, C_{2}, C_{3}\right\}, \\
& S_{2}=\left\{C_{4}, C_{5}\right\}, \\
& S_{3}=\left\{C_{6}\right\}, \\
& S_{4}=\left\{C_{7}\right\}, \\
& S_{5}=\{\varnothing\} \\
& S_{6}=\left\{C_{8}\right\} .
\end{aligned}
$$

Step 3 Using expression (2) we obtained the maximum value of the criteria comparison scale

$$
r=\max \left\{\left|S_{1}\right|,\left|S_{2}\right|,\left|S_{3}\right|,\left|S_{4}\right|,\left|S_{5}\right|,\left|S_{6}\right|\right\}=3
$$

Therefore, criteria comparison scale is in range $I_{i p} \in\{0, \ldots 1, \ldots 3\}$. In this step, we once again relied on the experts who conducted comparison on each level. For the final value of comparison of two criteria, we took the middle value of comparisons of all experts and we obtained following values:

$$
\begin{aligned}
& \text { Level } S_{1}: I_{1}=0, I_{2}=0.6, I_{3}=3 . \\
& \text { Level } S_{2}: I_{4}=1.2, I_{5}=2 . \\
& \text { Level } S_{3}: I_{6}=0.7 . \\
& \text { Level } S_{4}: I_{7}=1.1 . \\
& \text { Level } S_{6}: I_{8}=1.5 .
\end{aligned}
$$


Step 4 Elasticity coefficient needs to be $r_{0} \geq 4$, in this particular case, we defined $r_{0}=4$.

Step 5 Defining criteria influence function using Eq. (3):

$$
f\left(C_{1}\right)=\frac{4}{1 \cdot 4+0}=1 ; f\left(C_{2}\right)=\frac{4}{1 \cdot 4+0.6}=0.869 ; \ldots f\left(C_{8}\right)=\frac{4}{6 \cdot 4+1.5}=0.157
$$

Step 6 Using expression (4) we calculated the weight coefficient of the most influential criterion:

$$
w_{1}=\frac{1}{1+0.869+\ldots+0.157}=0.25
$$

Values of weight coefficients of the rest of criteria are obtained using Eq. (5).

$$
\begin{aligned}
& w_{2}=0.869 \cdot 0.251=0.218 \\
& \ldots \\
& w_{8}=0.157 \cdot 0.251=0.039 .
\end{aligned}
$$

We obtained following weight coefficients:

$$
w_{j}=(0.25,0.22,0.14,0.11,0.1,0.08,0.06,0.04) .
$$

After calculations of weight coefficients, we can move on to the next phase of the model.

\section{Selection of the Best Alternative Using the IR-MAIRCA Method}

The third phase of using the model implies using the IR-MAIRCA method, according to the steps described in the second part of this paper. A part of data about alternatives was taken from the existing literature, whereas a part of it was obtained through different kinds of measurements and estimations.

Step 1 In the first step of using the IR-MAIRCA method, we formed the initial decisionmaking matrix $(Y)$, Table 1, where all the alternatives have been evaluated based on all criteria.

Table 1 Initial decision-making matrix $(Y)$

\begin{tabular}{cccccc}
\hline Alter- & \multicolumn{5}{c}{ Criteria } \\
\cline { 2 - 6 } natives & $\mathrm{C}_{1}$ & $\mathrm{C}_{2}$ & $\mathrm{C}_{3}$ & & \\
\hline $\mathrm{A}_{1}$ & {$[(640,715),(777,930)]$} & {$[(76,88),(95,98)]$} & {$[(92,115),(145,195)]$} & $\ldots$ & {$[(264,376),(406,406)]$} \\
$\mathrm{A}_{2}$ & {$[(714,800),(825,870)]$} & {$[(85,101),(122,127)]$} & {$[(58,72),(91,121)]$} & $\ldots$ & {$[(58,72),(91,121)]$} \\
$\mathrm{A}_{3}$ & {$[(285,315),(375,400)]$} & {$[(9,11),(12,14)]$} & {$[(48,72),(95,129)]$} & $\ldots$ & {$[(48,72),(95,129)]$} \\
$\mathrm{A}_{4}$ & {$[(255,285),(370,410)]$} & {$[(8,9),(10,11)]$} & {$[(56,74),(93,125)]$} & $\ldots$ & {$[(56,74),(93,125)]$} \\
$\mathrm{A}_{5}$ & {$[(620,660),(680,700)]$} & {$[(3,3),(4,5)]$} & {$[(59,84),(96,148)]$} & $\ldots$ & {$[(59,84),(96,148)]$} \\
$\mathrm{A}_{6}$ & {$[(400,465),(485,500)]$} & {$[(17,24),(26,29)]$} & {$[(51,63),(132,175)]$} & $\ldots$ & {$[(51,63),(132,175)]$} \\
$\mathrm{A}_{7}$ & {$[(270,330),(378,422)]$} & {$[(14,17),(21,22)]$} & {$[(39,58),(91,132)]$} & $\ldots$ & {$[(130,150),(175,175)]$} \\
$\mathrm{A}_{8}$ & {$[(250,260),(267,290)]$} & {$[(33,38),(40,43)]$} & {$[(39,49),(78,108)]$} & $\ldots$ & {$[(140,170),(410,470)]$} \\
$\mathrm{A}_{9}$ & {$[(315,370),(377,405)]$} & {$[(113,167),(194,211)]$} & {$[(60,74),(94,126)]$} & $\ldots$ & {$[(238,255),(305,367)]$} \\
$\mathrm{A}_{10}$ & {$[(320,344),(370,380)]$} & {$[(83,92),(106,115)]$} & {$[(97,119),(172,222)]$} & $\ldots$ & {$[(195,225),(230,230)]$} \\
\hline \multicolumn{7}{c}{}
\end{tabular}


Step 2 Decision-makers did not have different preferences towards the choice of alternatives, therefore, $P_{A_{i}}$ was determined using Eq. (13):

$$
P_{A_{i}}=\frac{1}{10}=0.1
$$

Step 3 Elements of theoretical estimations matrix $\left(T_{p}\right)$ were calculated using expression (14), Table 2

Table 2 Theoretical estimations matrix $\left(T_{p}\right)$

\begin{tabular}{|c|c|c|c|c|c|}
\hline \multirow{2}{*}{$\begin{array}{l}\text { Alter- } \\
\text { natives }\end{array}$} & \multicolumn{5}{|c|}{ Criteria } \\
\hline & $\mathrm{C}_{1}$ & $\mathrm{C}_{2}$ & $\mathrm{C}_{3}$ & & $\mathrm{C}_{8}$ \\
\hline $\mathrm{A}_{1-10}$ & $\begin{array}{c}{[(0.025,0.025),} \\
(0.025,0.025)]\end{array}$ & $\begin{array}{c}{[(0.022,0.022),} \\
(0.022,0.022)]\end{array}$ & $\begin{array}{l}{[(0.014,0.014),} \\
(0.014,0.014)]\end{array}$ & $\cdots$ & $\begin{array}{c}{[(0.004,0.004),} \\
(0.004,0.004)]\end{array}$ \\
\hline
\end{tabular}

Step 4 Using Eqs. (18)-(21) we conducted normalization of elements of the initial decision-making matrix. Normalized initial matrix $(X)$ is shown in Table 3.

Table 3 Normalized initial decision-making matrix $(X)$

\begin{tabular}{ccccc}
\hline Alter- & \multicolumn{4}{c}{ Criteria } \\
\cline { 2 - 5 } natives & $\mathrm{C}_{1}$ & $\mathrm{C}_{2}$ & $\mathrm{C}_{8}$ \\
\hline $\mathrm{A}_{1}$ & {$[(0.574,0.684),(0.775,1)]$} & {$[(0.543,0.558),(0.591,0.649)] \ldots$} & {$[(0.42,0.735),(0.82,0.82)]$} \\
$\mathrm{A}_{2}$ & {$[(0.682,0.809),(0.846,0.912)]$} & {$[(0.404,0.428),(0.529,0.606)] \ldots$} & {$[(0.213,0.32),(0.392,0.606)]$} \\
$\mathrm{A}_{3}$ & {$[(0.051,0.096),(0.184,0.221)]$} & {$[(0.947,0.957),(0.962,0.971)] \ldots$} & {$[(0,0.087),(0.093,0.31)]$} \\
$\mathrm{A}_{4}$ & {$[(0.007,0.051),(0.176,0.235)]$} & {$[(0.962,0.966),(0.971,0.976)] \ldots$} & {$[(0.239,0.239),(0.239,0.239)]$} \\
$\mathrm{A}_{5}$ & {$[(0.544,0.603),(0.632,0.662)]$} & {$[(0.99,0.995),(1,1)]$} & $\ldots$ & {$[(0.183,0.183),(0.183,0.183)]$} \\
$\mathrm{A}_{6}$ & {$[(0.221,0.316),(0.346,0.368)]$} & {$[(0.875,0.889),(0.899,0.933)] \ldots$} & {$[(0.189,0.189),(0.211,0.211)]$} \\
$\mathrm{A}_{7}$ & {$[(0.029,0.118),(0.188,0.253)]$} & {$[(0.909,0.913),(0.933,0.947)] \ldots$} & {$[(0.042,0.099),(0.169,0.169)]$} \\
$\mathrm{A}_{8}$ & {$[(0,0.015),(0.025,0.059)]$} & {$[(0.808,0.822),(0.832,0.856)] \ldots$} & {$[(0.07,0.155),(0.831,1)]$} \\
$\mathrm{A}_{9}$ & {$[(0.096,0.176),(0.187,0.228)]$} & {$[(0,0.082),(0.212,0.471)]$} & $\ldots$ & {$[(0.346,0.394),(0.535,0.71)]$} \\
$\mathrm{A}_{10}$ & {$[(0.103,0.138),(0.176,0.191)]$} & {$[(0.462,0.505),(0.572,0.615)] \ldots$} & {$[(0.225,0.31),(0.324,0.324)]$} \\
\hline \multicolumn{5}{c}{} \\
\hline
\end{tabular}

After normalization of the initial decision-making matrix we satisfied the conditions to calculate elements of real estimations matrix $\left(T_{r}\right)$. We calculate elements of the real estimations matrix using Eq. (16), Table 4.

Table 4 Real estimations matrix $\left(T_{r}\right)$

\begin{tabular}{|c|c|c|}
\hline \multirow{2}{*}{$\begin{array}{l}\text { Alter- } \\
\text { natives }\end{array}$} & \multicolumn{2}{|r|}{ Criteria } \\
\hline & $\mathrm{C}_{1}$ & $\begin{aligned} & \mathrm{C}_{2} \mathrm{C}_{8} \\
&\end{aligned}$ \\
\hline $\mathrm{A}_{1}$ & {$[(0.014,0.017),(0.019,0.025)]$} & {$[(0.012,0.012),(0.013,0.014)] \ldots[(0.002,0.003),(0.003,0.003)]$} \\
\hline $\mathrm{A}_{2}$ & {$[(0.017,0.02),(0.021,0.023)]$} & {$[(0.009,0.009),(0.012,0.013)] \ldots[(0.001,0.001),(0.002,0.002)]$} \\
\hline $\mathrm{A}_{3}$ & {$[(0.001,0.002),(0.005,0.006)]$} & {$[(0.021,0.021),(0.021,0.021)] \ldots \quad[(0,0),(0,0.001)]$} \\
\hline $\mathrm{A}_{4}$ & {$[(0,0.001),(0.004,0.006)]$} & {$[(0.021,0.021),(0.021,0.021)] \ldots[(0.001,0.001),(0.001,0.001)]$} \\
\hline $\mathrm{A}_{5}$ & {$[(0.014,0.015),(0.016,0.017)]$} & {$[(0.022,0.022),(0.022,0.022)] \ldots[(0.001,0.001),(0.001,0.001)]$} \\
\hline $\mathrm{A}_{6}$ & {$[(0.006,0.008),(0.009,0.009)]$} & {$[(0.019,0.02),(0.02,0.021)] \ldots[(0.001,0.001),(0.001,0.001)]$} \\
\hline $\mathrm{A}_{7}$ & {$[(0.001,0.003),(0.005,0.006)]$} & {$[(0.02,0.02),(0.021,0.021)] \ldots \quad[(0,0),(0.001,0.001)]$} \\
\hline $\mathrm{A}_{8}$ & {$[(0,0),(0.001,0.001)]$} & {$[(0.018,0.018),(0.018,0.019)] \ldots \quad[(0,0.001),(0.003,0.004)]$} \\
\hline $\mathrm{A}_{9}$ & {$[(0.002,0.004),(0.005,0.006)]$} & {$[(0,0.002),(0.005,0.01)] \quad \ldots[(0.001,0.002),(0.002,0.003)]$} \\
\hline $\mathrm{A}_{10}$ & {$[(0.003,0.003),(0.004,0.005)]$} & {$[(0.01,0.011),(0.013,0.014)] \ldots[(0.001,0.001),(0.001,0.001)]$} \\
\hline
\end{tabular}


Step 5 In this step, using expression (22), we calculated gap matrix ( $G$ ), Table 5.

Table 5 Gap matrix $(G)$

\begin{tabular}{ccccc}
\hline Alter- & \multicolumn{4}{c}{ Criteria } \\
\cline { 2 - 6 } natives & $\mathrm{C}_{1}$ & $\mathrm{C}_{2}$ & $\mathrm{C}_{8}$ \\
\hline $\mathrm{A}_{1}$ & {$[(0,0.006),(0.008,0.011)]$} & {$[(0.008,0.009),(0.01,0.01)]$} & $\ldots$ & {$[(0.001,0.001),(0.001,0.002)]$} \\
$\mathrm{A}_{2}$ & {$[(0.002,0.004),(0.005,0.008)]$} & {$[(0.009,0.01),(0.013,0.013)]$} & $\ldots$ & {$[(0.002,0.002),(0.003,0.003)]$} \\
$\mathrm{A}_{3}$ & {$[(0.019,0.02),(0.023,0.024)]$} & {$[(0.001,0.001),(0.001,0.001)]$} & $\ldots$ & {$[(0.003,0.004),(0.004,0.004)]$} \\
$\mathrm{A}_{4}$ & {$[(0.019,0.021),(0.024,0.025)]$} & {$[(0.001,0.001),(0.001,0.001)]$} & $\ldots$ & {$[(0.003,0.003),(0.003,0.003)]$} \\
$\mathrm{A}_{5}$ & {$[(0.008,0.009),(0.01,0.011)]$} & {$[(0,0),(0,0)]$} & $\ldots$ & {$[(0.003,0.003),(0.003,0.003)]$} \\
$\mathrm{A}_{6}$ & {$[(0.016,0.016),(0.017,0.019)]$} & {$[(0.001,0.002),(0.002,0.003)]$} & $\ldots$ & {$[(0.003,0.003),(0.003,0.003)]$} \\
$\mathrm{A}_{7}$ & {$[(0.019,0.02),(0.022,0.024)]$} & {$[(0.001,0.001),(0.002,0.002)]$} & $\ldots$ & {$[(0.003,0.003),(0.004,0.004)]$} \\
$\mathrm{A}_{8}$ & {$[(0.024,0.024),(0.025,0.025)]$} & {$[(0.003,0.004),(0.004,0.004)]$} & $\ldots$ & {$[(0,0.001),(0.003,0.004)]$} \\
$\mathrm{A}_{9}$ & {$[(0.019,0.02),(0.021,0.023)]$} & {$[(0.012,0.017),(0.02,0.022)]$} & $\ldots$ & {$[(0.001,0.002),(0.002,0.003)]$} \\
$\mathrm{A}_{10}$ & {$[(0.02,0.021),(0.022,0.022)]$} & {$[(0.008,0.009),(0.011,0.012)]$} & $\ldots$ & {$[(0.003,0.003),(0.003,0.003)]$} \\
\hline
\end{tabular}

Step 6 Using expression (24) we calculated values of criteria functions $\left(Q_{i}\right)$ by alternatives, that is calculation of total gap, Table 6 .

Table 6 Matrix of total gap

\begin{tabular}{cc}
\hline Alternatives & Alternatives gap $\operatorname{IRN}\left(Q_{i}\right)$ \\
\hline $\mathrm{A}_{1}$ & {$[(0.025,0.038),(0,0.058)]$} \\
$\mathrm{A}_{2}$ & {$[(0.031,0.042),(0,0.061)]$} \\
$\mathrm{A}_{3}$ & {$[(0.046,0.056),(0,0.071)]$} \\
$\mathrm{A}_{4}$ & {$[(0.047,0.053),(0,0.067)]$} \\
$\mathrm{A}_{5}$ & {$[(0.032,0.038),(0,0.049)]$} \\
$\mathrm{A}_{6}$ & {$[(0.036,0.046),(0,0.061)]$} \\
$\mathrm{A}_{7}$ & {$[(0.041,0.05),(0,0.066)]$} \\
$\mathrm{A}_{8}$ & {$[(0.056,0.065),(0,0.08)]$} \\
$\mathrm{A}_{9}$ & {$[(0.059,0.074),(0,0.091)]$} \\
$\mathrm{A}_{10}$ & {$[(0.047,0.058),(0,0.074)]$} \\
\hline
\end{tabular}

Further on, using Eqs. (25) and (26) we converted interval rough numbers to real numbers; based on this, we defined the initial ranking of alternatives, Table 7.

Table 7 Initial ranking of alternatives

\begin{tabular}{ccc}
\hline Alternatives & Alternatives gap $Q_{i}$ & $\begin{array}{c}\text { Initial ranking of } \\
\text { alternatives }\end{array}$ \\
\hline $\mathrm{A}_{1}$ & 0.0445 & 2 \\
$\mathrm{~A}_{2}$ & 0.0467 & 3 \\
$\mathrm{~A}_{3}$ & 0.0599 & 7 \\
$\mathrm{~A}_{4}$ & 0.059 & 6 \\
$\mathrm{~A}_{5}$ & 0.0415 & 1 \\
$\mathrm{~A}_{6}$ & 0.049 & 4 \\
$\mathrm{~A}_{7}$ & 0.0538 & 5 \\
$\mathrm{~A}_{8}$ & 0.0692 & 9 \\
$\mathrm{~A}_{9}$ & 0.0796 & 10 \\
$\mathrm{~A}_{10}$ & 0.062 & 8 \\
\hline
\end{tabular}


Step 7 In the last step of the IR-MAIRCA method, the dominance index of the firstranked alternative is determined using Eq. (27), as well as the exact final ranking of alternatives, Table 8. Since Eq. (28) yielded dominance threshold $I_{D}=0.09$, we notice that the advantage of initially first-ranked alternative $\left(A_{5}\right)$ is not significant enough compared to second-ranking $\left(\mathrm{A}_{1}\right)$ and third-ranking alternative $\left(\mathrm{A}_{2}\right)$. Therefore, we can conclude that the decision-maker can choose any of the listed alternatives as the first-ranking one. This is a significant characteristic of the MAIRCA method considering to a certain extent the omnipresent subjectivity of decision-makers while defining entrance parameters for weight coefficient criteria calculations. In the practical sense, during the last step of the MAIRCA (IR -MAIRCA) method, we take into consideration errors while defining criteria of weight coefficients, regardless of the methods used to determine the weight coefficients.

Table 8 Final ranking of alternatives

\begin{tabular}{ccc}
\hline Alternatives & Dominance index $\left(A_{D, 1-1}\right)$ & Final ranking of alternatives \\
\hline $\mathrm{A}_{1}$ & 0.037 & $1^{*}$ \\
$\mathrm{~A}_{2}$ & 0.065 & $1^{* *}$ \\
$\mathrm{~A}_{3}$ & 0.230 & 7 \\
$\mathrm{~A}_{4}$ & 0.219 & 6 \\
$\mathrm{~A}_{5}$ & 0.000 & 1 \\
$\mathrm{~A}_{6}$ & 0.094 & 4 \\
$\mathrm{~A}_{7}$ & 0.154 & 5 \\
$\mathrm{~A}_{8}$ & 0.348 & 9 \\
$\mathrm{~A}_{9}$ & 0.478 & 10 \\
$\mathrm{~A}_{10}$ & 0.257 & 8 \\
\hline
\end{tabular}

From obtained rankings, we can conclude that the construction elements of the new type of the close-quarters combat weapon, or modifications to the existing ones, have to be based on the characteristics of first-ranked alternatives $A_{1}, A_{2}$ and $A_{5}$. The initial request of the users gives the best characteristics of these three types of weapons, which would be adjusted to realistic possibilities for construction. Through the developed model of multi-criteria decision-making, we can constantly compare requests for the new close-quarters combat weapon with the existing ones, and by doing that, we can conduct checks and corrections. This would lead to maximization of the weapon's characteristics by the user; at the same time, the constructor would have the ability to constantly check the quality of his work in practice.

\section{SENSITIVITY ANALYSIS}

Sensitivity analysis is the last step that needs to be applied. Weak results of sensitivity analysis take the whole research process to the beginning [35]. There are different approaches to the sensitivity analysis of models; most often authors in their papers use sensitivity analysis by changing weight coefficients of criteria [36]. This analysis implies evaluation of alternatives based on different weight coefficients of criteria, that is favoring one criterion in each scenario. In this research we defined eight scenarios, Table 9. 
Table 9 Weight coefficients of criteria in different scenarios

\begin{tabular}{cccccccccc}
\hline Criteria & S-0 & S-1 & S-2 & S-3 & S-4 & S-5 & S-6 & S-7 & S-8 \\
\hline $\mathrm{C}_{1}$ & 0.25 & 0.3 & 0.1 & 0.1 & 0.1 & 0.1 & 0.1 & 0.1 & 0.1 \\
$\mathrm{C}_{2}$ & 0.22 & 0.1 & 0.3 & 0.1 & 0.1 & 0.1 & 0.1 & 0.1 & 0.1 \\
$\mathrm{C}_{3}$ & 0.14 & 0.1 & 0.1 & 0.3 & 0.1 & 0.1 & 0.1 & 0.1 & 0.1 \\
$\mathrm{C}_{4}$ & 0.11 & 0.1 & 0.1 & 0.1 & 0.3 & 0.1 & 0.1 & 0.1 & 0.1 \\
$\mathrm{C}_{5}$ & 0.10 & 0.1 & 0.1 & 0.1 & 0.1 & 0.3 & 0.1 & 0.1 & 0.1 \\
$\mathrm{C}_{6}$ & 0.08 & 0.1 & 0.1 & 0.1 & 0.1 & 0.1 & 0.3 & 0.1 & 0.1 \\
$\mathrm{C}_{7}$ & 0.06 & 0.1 & 0.1 & 0.1 & 0.1 & 0.1 & 0.1 & 0.3 & 0.1 \\
$\mathrm{C}_{8}$ & 0.04 & 0.1 & 0.1 & 0.1 & 0.1 & 0.1 & 0.1 & 0.1 & 0.3 \\
\hline
\end{tabular}

Rankings of alternatives obtained using different scenarios are shown in Table 10.

Table 10 Rankings of alternatives obtained using different scenarios

\begin{tabular}{cccccccccc}
\hline Criteria & S-0 & S-1 & S-2 & S-3 & S-4 & S-5 & S-6 & S-7 & S-8 \\
\hline $\mathrm{A}_{1}$ & $1(2)$ & 1 & 2 & 1 & 2 & 4 & 1 & 1 & 1 \\
$\mathrm{~A}_{2}$ & $1(3)$ & 2 & 7 & 3 & 1 & 5 & 5 & 2 & 2 \\
$\mathrm{~A}_{3}$ & 7 & 8 & 6 & 8 & 8 & 8 & 8 & 5 & 9 \\
$\mathrm{~A}_{4}$ & 6 & 7 & 5 & 7 & 7 & 6 & 7 & 4 & 7 \\
$\mathrm{~A}_{5}$ & 1 & 3 & 1 & 2 & 3 & 2 & 3 & 3 & 3 \\
$\mathrm{~A}_{6}$ & 4 & 4 & 3 & 4 & 4 & 1 & 2 & 6 & 4 \\
$\mathrm{~A}_{7}$ & 5 & 5 & 4 & 6 & 5 & 3 & 4 & 7 & 5 \\
$\mathrm{~A}_{8}$ & 9 & 9 & 9 & 9 & 9 & 9 & 9 & 10 & 8 \\
$\mathrm{~A}_{9}$ & 10 & 10 & 10 & 10 & 10 & 10 & 10 & 9 & 10 \\
$\mathrm{~A}_{10}$ & 8 & 6 & 8 & 5 & 6 & 7 & 6 & 8 & 6 \\
\hline
\end{tabular}

Obtained rankings, shown in Table 10, imply that favoring certain criteria affects the differences in rankings; this further implies that the developed model is sensitive to the changes of weight coefficients. Rankings of alternatives by different scenarios are visible in the graph below, Fig. 2.

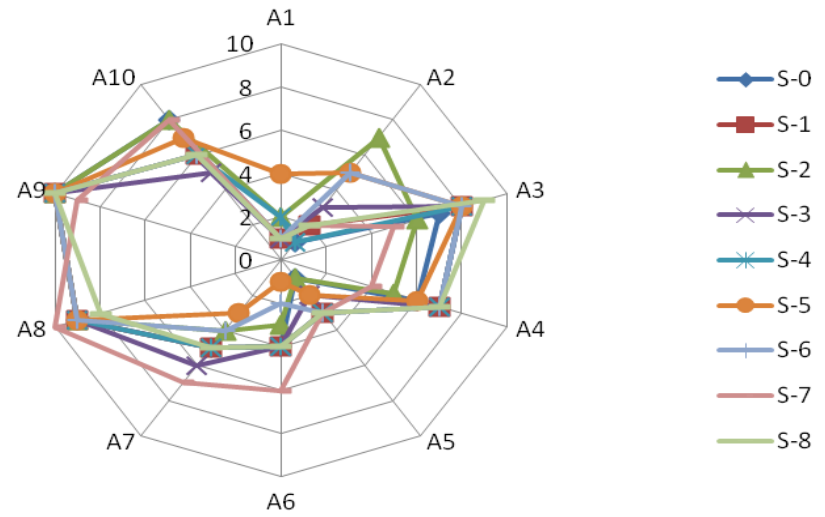

Fig. 2 Graph of alternatives rankings by scenarios 
Worst-ranked alternatives $\left(\mathrm{A}_{8}, \mathrm{~A}_{9}\right)$ in a large number of scenarios kept their rankings, as well as best-ranked ones $\left(\mathrm{A}_{5}, \mathrm{~A}_{1}, \mathrm{~A}_{2}\right)$. However, even though the correlation between rankings seems pretty obvious, a serious analysis demands quantitative indicators. In that sense, we checked rankings correlation using the Spearman's rank coefficient:

$$
S=1-\frac{6 \sum_{i=1}^{n} D_{i}^{2}}{n\left(n^{2}-1\right)}
$$

where: $\mathrm{S}$ - the value of the Spirman coefficient; $\mathrm{D}_{\mathrm{i}}$ - the difference in the rank of the given element in vector $\mathrm{w}$ and the rank of the correspondent element in the reference vector; $\mathrm{n}$ number of ranked elements. The values of the Spearman's coefficients range from -1 ("ideal negative correlation") up to 1 ("ideal positive correlation").

In Table 11, one can see values of the Spearman's coefficients by comparing all scenarios to each other. In the first row of Table 11, when comparing scenario S-0 (values of weight coefficients obtained through research) to others we got values compared to the final ranking - values outside of the parentheses and compared to the initial ranking (values inside of parentheses).

Table 11 Rankings of alternatives obtained using different scenarios

\begin{tabular}{cccccccccc}
\hline $\begin{array}{c}\text { Sce- } \\
\text { narios }\end{array}$ & S-0 & S-1 & S-2 & S-3 & S-4 & S-5 & S-6 & S-7 & S-8 \\
\hline S-0 & 1 & $0.93(0.93)$ & $0.75(0.88)$ & $0.90(0.92)$ & $0.93(0.92)$ & $0.75(0.85)$ & $0.81(0.88)$ & $0.86(0.85)$ & $0.91(0.90)$ \\
S-1 & 1 & 0.73 & 0.98 & 0.99 & 0.79 & 0.92 & 0.81 & 0.99 \\
S-2 & & 1 & 0.76 & 0.67 & 0.88 & 0.87 & 0.68 & 0.70 \\
S-3 & & & 1 & 0.95 & 0.78 & 0.91 & 0.78 & 0.96 \\
S-4 & & & & 1 & 0.78 & 0.87 & 0.79 & 0.98 \\
S-5 & & & & & 1 & 0.91 & 0.54 & 0.78 \\
S-6 & & & & & & & & 0.65 & 0.90 \\
S-7 & & & & & & & & & 0.75 \\
S-8 & & & & & & & & & \\
\hline
\end{tabular}

From Table 11 we can see that the correlation of rankings by scenarios is very high. Certainly the most important correlation on rankings is between scenarios S-0 and others, where the value of Spearman's coefficient does not go below 0.75 ; it is a satisfactory value. The lowest correlation of rankings is between scenarios S-5 and S-7 (0.54); however, it is expected for lower correlations to exist in situations where the weight coefficient of criteria increases significantly. Essentially, there are no scenarios where the correlation is absent; neither is there a scenario whose correlation approaches ideally uncorrelated rankings. This implies that using this model, that is the IR-MAIRCA method, we can reach good solutions, even in the cases when weight coefficients deviate from realistic requests. 


\section{CONCLUSION}

In this paper, we have demonstrated the use of LBWA - IR-MAIRCA model when selecting the close-quarters combat weapon that is most suitable for tasks executed by the members of the Serbian Army equipped with this kind of weapons. Based on the selected weapon, one with the best characteristics, we can plan constructing a new weapon, or modifying an existing one; this we can do on the basis of realistic requests and realistic capacities of the constructor. Throughout the paper, we have demonstrated all phases of developing and using a multi-criteria decision-making model. We have defined the selection-affecting criteria and calculated their weight coefficients using the LBWA method. This method has proved to be very applicable and simple in the process of collecting data from the experts. The choice of the best alternative was done using the MAIRCA method, which was improved using interval rough numbers which significantly improved the decision-making process since it opened possibilities for observing characteristics of each weapon. A significant step of this method, determining the first-ranked alternative in relation to others, made three alternatives first-ranking. This is significant since the MAIRCA method additionally eliminates subjectivity when making decisions.

We have also conducted sensitivity analysis of the model. Results obtained from sensitivity analysis show that output values (rankings of alternatives) change depending on weight coefficients. On the other hand, changes in rankings while changing weight coefficients of criteria, demonstrated clearly the dominance of the first-ranked alternatives. Everything listed above implies that the model provides the same or similar results, regardless of possible minor errors that can occur in the process of defining weight coefficients of the criteria, as a consequence of subjectivity of experts, that is, the decision-makers.

Throughout future research, this model could be applied when solving other research problems.

Acknowledgements: This paper was written under the VA-DH/1/18- 20 project financed by the Ministry of Defense of the Republic of Serbia.

\section{REFERENCES}

1. Jenzen-Jones, N.R., Schroeder, M., 2018, An Introductory Guide to the Identification of Small Arms, Light Weapons, and Associated Ammunition, Small Arms Survey, Graduate Institute of International and Development Studies, Geneva.

2. Tančić, LJ., Regodić, D., Ristić, Z., Kari, A., Vasiljević, D., Maričić, Z., 2009, Handling and maintenance of weapons (Only in Serbian: Poznavanje i održavanje naoružanja), Military publishing institute/Vojnoizdavački zavod, Belgrdae, Serbia.

3. Dağdeviren, M., Yavuz, S., Kılınç, N., 2009, Weapon selection using the AHP and TOPSIS methods under fuzzy environment, Expert systems with applications, 36(4), pp. 8143-8151.

4. Ashari, H., Parsaei, M., 2014, Application of the multi-criteria decision method ELECTRE III for the Weapon selection, Decision Science Letters, 3(4), pp. 511-522.

5. Radovanović, M., Ranđelović, A., Milić, A., 2019, Comparative analysis of anti-armor systems using the AHP method, Vojno delo, 71(7), pp. 234-250.

6. Jokić Ž., Delibašić B., Komljenović S., 2019, Implementation of the VIKOR method when selecting the caliber for automatic rifles for operational use in the SAF units, Vojno delo, 71(6), pp. 200-221.

7. Brady, M., Goethals, P., 2019, A comparative analysis of contemporary 155 mm artillery projectiles, Journal of Defense Analytics and Logistics, 3(2), pp. 171-192. 
8. Jenkins, S., Lowrey D., 2004, A Comparative Analysis Of Current And Planned Small Arms Weapon Systems, MBA Professional Report, Naval Postgraduate School Monterey, California, USA.

9. Gordon, J., Matsumura, J., Atler, A., Boston, S.S., Boyer, M.E., Lander, N., Nichols, T.W., 2015, Comparing U.S. Army Systems with Foreign Counterparts: Identifying Possible Capability Gaps and Insights from Other Armies, RAND Corporation, Santa Monica, USA.

10. Radovanović, M., Ranđelović, A., Blagojević A., 2018, Comparative analysis of anti - armoured rocket systems, Proc. Twenty-first DQM International Conference Dependability and Quality Management ICDQM 2018, Prijevor, Serbia, pp. $452-459$.

11. Žižović, M., Pamučar, D., 2019, New model for determining criteria weights: Level Based Weight Assessment (LBWA) model, Decision Making: Applications in Management and Engineering, 2(2), pp. 126-137.

12. Wang, J., Tang, P, 2011, A rough random multiple criteria decisionmaking method based on Interval rough operator, Control and decision making, 26(7), pp. 1056-1059.

13. Pamučar, D., Mihajlović, M., Obradović, R., Atanasković, P., 2017, Novel approach to group multi-criteria decision making based on interval rough numbers: Hybrid DEMATEL-ANP-MAIRCA model, Expert Systems With Applications, 88, pp. 58-80.

14. Pamučar, D., Stević, Ž., Zavadskas, E.K., 2018, Integration of interval rough AHP and interval rough MABAC methods for evaluating university web pages, Applied soft computing, 67, pp. 141-163.

15. Pamučar, D., Chatterjee, K., Zavadskas, E.K., 2019, Assessment of third-party logistics provider using multicriteria decision- making approach based on interval rough numbers, Computers \& Industrial Engineering, 127, pp. 383-407.

16. Pamučar, D., Vasin, Lj., Lukovac, L., 2014, Selection of railway level crossings for investing in security equipment using hybrid DEMATEL-MARICA model, Proc. Sixteenth International Scientific-expert Conference on Railway, Railcon 2014, Niš, Serbia, pp. 89-92.

17. Gigović, Lj., Pamučar, D., Bajić, Z., Milićević, M., 2016, The Combination of Expert Judgment and GISMAIRCA Analysis for the Selection of Sites for Ammunition Depots, Sustainability, 8, no. 372.

18. Pamučar, D., Lukovac, V., Božanić, D., Komazec, N., 2018, Multi-criteria FUCOM - MAIRCA model for the evaluation of level crossings: Case study in the Republic of Serbia, Operational Research in Engineering Sciences: Theory and Applications, 1(1), pp. 108-129.

19. Tešić, D., Božanić, D., 2018, Application of the MAIRCA method in the selection of the location for crossing tanks under water, Tehnika, 68(6), pp. 860-867.

20. Adar, T., Delice, E.K, 2019, An Integrated MC-HFLTS \& MAIRCA Method and Application in Cargo Distribution Companies, International Journal of Supply and Operations Management, 6(3), pp. $276-281$.

21. Ayçin, E., Orçun, Ç., 2019, Evaluation of Performance of Deposit Banks by Entropy and MAIRCA Methods, Balıkesir University The Journal of Social Sciences Institute, 22(42), pp. 175-194.

22. Adar, T., Delice, E.K, 2020, New integrated approaches based on MC-HFLTS for healthcare waste treatment technology selection, Journal of Enterprise Information Management, 32(4), 688-711.

23. Ayçin, E., 2020, Personel Seçim Sürecinde CRITIC ve MAIRCA Yöntemlerinin Kullanılması, İșletme, 1(1), pp. $1-12$.

24. Chatterjee, K., Pamučar, D., Zavadskas, E. K., 2018, Evaluating the performance of suppliers based on using the R'AMATEL-MAIRCA method for green supply chain implementation in electronics industry, Journal of Cleaner Production, 184, pp. 101-129.

25. Badi, I., Ballem, M., 2018, Supplier selection using the rough BWM-MAIRCA model: A case study in pharmaceutical supplying in Libya, Decision Making: Applications in Management and Engineering, 1(2), pp. 16-33.

26. Stević, Ž., 2018, An integrated model for supplier evaluation in supply chains, PhD Thesis, Faculty of Technical Sciences, University of Novi Sad, Serbia.

27. Božanić, D., Pamučar, D., Tešić, D., 2019, Selection of the location for construction, reconstruction and repair of flood defense facilities by IR-MAIRCA model application, Proc. Fifth International Scientific-Profesional Conference Security and Crisis Management - Theory and Practice, SeCMan 2019, Belgrade, Serbia, pp. 300-308

28. Arsić, S., Pamučar, D., Suknović, M., Janošević, M., 2019, Menu evaluation based on rough MAIRCA and BW methods, Serbian journal of management, 14(1), pp. 27-48.

29. Hashemkhani Z.S., Fatih, A., Pamučar, D., Raslanas, S., 2020, Neighborhood selection for a newcomer via a novel BWM based the revised MAIRCA integrated, Journal of Strategic Property Management, 24(2), pp. 102-118. 
30. Boral, S, Howard, I., Chaturvedi, S.K., McKee, K., Naikan, V.N.A., 2020, An integrated approach for fuzzy failure modes and effects analysis using fuzzy AHP and fuzzy MAIRCA, Engineering Failure Analysis, 108, paper no. 104195.

31. Pamučar, D., Božanić, D., Milić, A., 2016, Selection of a course of action by Obstacle Employment Group based on a fuzzy logic system, Yugoslav Journal of Operations Research, 26(1), pp. 75-90.

32. Ranđelović, A., Komazec, N., 2016, Safe handling of pistols and revolvers (Only in Serbian: Bezbedno rukovanje pištoljima i revolverima), S4 Global Security, Belgrade, Serbia.

33. Randjelović, A., Radovanović, M., Stevanović, M., 2019, Comparative analysis of anti - tank missile systems using the AHP method in order to equip units of the Serbian army, Proc. Twenty-second DQM International Conference Dependability and Quality Management ICDQM 2019, Prijevor, Serbia, pp. 336 - 344.

34. Jones, R., Ness, L., 2008, Jane's Infantry Weapons 2008-2009, Ihs, Coulsdon, United Kingdom.

35. Biswas, T.K., Chaki, S., Das, M.C., 2019, MCDM technique application to the selection of an Indian institute of technology, Operational Research in Engineering Sciences: Theory and Applications, 2(3), pp. 65-76.

36. Pamučar, D., Božanić, D., Ranđelović, A., 2017, Multi-criteria decision making: An example of sensitivity analysis, Serbian Journal of Management, 12(1), pp. 1-27. 